\title{
Comparación entre la aplicación de calor local mediante un dispositivo termoeléctrico, aseos palpebrales con champú del aceite del árbol de té y tratamiento convencional en pacientes con disfunción de glándulas de meibomio de la tercera edad
}

Natalia Hernández-Martínez*, Oscar Fernández-Vizcaya, Cristina Pacheco-Del Valle, Regina Velasco-Ramos, Alejandro Babayán-Sosa, Elisa Alegría-Gómez, Diana Raya-Hernández and Oscar Baca-Lozada

Department of cornea and refractive surgery, Fundación Hospital Nuestra Señora de la Luz, IAP, Mexico City, Mexico

\begin{abstract}
Purpose: To compare the efficacy between a thermoelectric heating device (MiBoFlo Thermoflo ${ }^{\circ}$ ), tea tree shampoo eyelid scrubs and baby shampoo eyelid scrubs in elderly patients with Meibomian gland dysfunction (MGD). Materials and methods: prospective, interventional, longitudinal and comparative study. Forty-one elderly patients (82 eyes) were included. Patients were divided in three groups. Group I $(n=30)$ : patients received 3 sessions with Thermoflo. Group II $(n=26)$ : tea tree shampoo eyelid scrubs. Group III $(n=26)$ : control, with baby shampoo. Ophthalmologic examination included baseline secretion test with topical anesthesia, tear break-up time (TBUT), ocular surface fluorescein staining with the Oxford scheme, Meibomian gland (MG) assessment (meibum quality and expressibility) and Ocular Surface Disease Index (OSDI) questionnaire. Evaluations were made at baseline, 4 and 8 weeks post-treatment. Repeated measures ANOVA with Greenhouse-Geisser correction was used to determine significant changes between groups. Results: There were statistically significant changes in Oxford, meibum quality and gland expressibility between the groups. OSDI score and TBUT showed improvement, but were not statistically significant. Conclusion: Apparently Thermoflo and tea tree shampoo treatments were superior for the improvement of signs and symptoms associated with MGD. Thermoflo seems superior in improving obstructive MGD due to greater gland expressibility.
\end{abstract}

Key words: Meibomian glands. Eyelid diseases. Dry eye syndromes. Dysfunction. Comparative study.

\section{Resumen}

Objetivo: Comparar la eficacia entre un dispositivo de calor termoeléctrico (MiBoFlo Thermoflo'), aseos palpebrales con champú del árbol de té y aseos convencionales con champú de bebé en pacientes con disfunción de las glándulas de meibomio (DGM) de la tercera edad. Método: estudio prospectivo, intervencional, longitudinal y comparativo. Se incluyeron

\section{Correspondence:}

*Natalia Hernández-Martínez

FHNSL, C. Ezequiel Montes 135, Cuauhtémoc, Date of reception: 15-03-2018

Tabacalera, 06030 Mexico City, Mexico Date of acceptance: 31-07-2018

E-mail: nataliahrz@gmail.com DOI: 10.24875/RMOE.M18000038

2604-1731/O 2018 Sociedad Mexicana de Oftalmología Published by Permanyer México SA de CV. This is an Open Access article und license (http://creativecommons.org/licenses/by-nc-nd/4.0/). 
41 pacientes (82 ojos), que se dividieron en 3 grupos. Grupo I $(n=30)$ : 3 sesiones de tratamiento con Thermoflo. Grupo II ( $n=26)$ : aseos palpebrales con champú del árbol de té. Grupo III $(n=26)$ : control, aseos palpebrales convencionales con champú de bebé. La exploración oftalmológica incluyó la prueba de secreción basal con anestesia, tiempo de ruptura lagrimal (TBUT), puntuación de Oxford con fluoresceína, puntuación de la secreción de las glándulas de Meibomio y aplicación del índice de enfermedad de la superficie ocular (OSDI) con medición basal, 4 y 8 semanas posteriores al tratamiento. Se aplicó la prueba de análisis de varianza entre grupos para mediciones repetidas utilizando el modelo de Greenhouse-Geisser para determinar cambios significativos entre los grupos. Resultados: Se observaron diferencias estadísticamente significativas en Oxford, calidad y expresibilidad del meibum entre los grupos. Se observó una disminución en el OSDI y aumento del TBUT, aunque los cambios no fueron significativos. Conclusiones: al parecer, el tratamiento con Thermoflo $y$ champú del árbol de té fue superior a los aseos palpebrales convencionales con champú de bebé en mejorar la sintomatología de los pacientes y los signos asociados a la DGM. Thermoflo parece ser superior en producir un mayor incremento de la expresibilidad de las glándulas de Meibomio.

Palabras clave: Glándulas de Meibomio. Enfermedades de los párpados. Síndromes de ojo seco. Disfunción. Estudio comparativo.

\section{Introduction}

Currently, Meibomian gland dysfunction (MGD) is recognized as the main cause of evaporative dry eye ${ }^{1-4}$. MGD can is divided into one type associated with a low level of secretion (hiposecretory and obstructive) and another type associated with gland hypersecretion (Meibomian seborrhea) $)^{5}$. However, MGD is mainly caused by blockage of the terminal portion of the ducts due to hyperkeratinization of the ductal epithelium and increased viscosity of the meibum. The obstructive process is influenced by endogenous factors, such as age, sex, hormonal changes, as well as exogenous factors such as topical medications ${ }^{3,5-7}$. The increase in intraglandular pressure caused by meibum stasis aggravates the obstruction and may result in gland atrophy ${ }^{2}$. The result is an alteration of the tear film, symptoms of dry eye, clinically apparent inflammation and ocular surface disease ${ }^{3,8,9}$.

The aim of MGD treatment is to improve the flow of Meibomian glands secretions. Traditional treatments include warm compresses, massage and eyelid hygiene to remove the blockage, as well as the use of antibiotics and anti-inflammatories to improve meibum quality and suppress bacterial colonization and inflammation ${ }^{10}$. However, the use of warm compresses and manual expression of the glands are often ineffective and can be painful for the patient. The temperature necessary to soften the content of the Meibomian glands varies between 32 and $40^{\circ} \mathrm{C}$, according to different reports ${ }^{11}$.

Among the emerging treatments for Meibomian gland dysfunction is the MiBoFlo Thermoflo ${ }^{\circledR}$ that uses a thermoelectric heat pump that distributes a constant level of heat through an ultrasonic probe that contains two pads in its distal portion ${ }^{8}$. The tissues absorb the heat emitted at $42^{\circ} \mathrm{C}$, which causes the hardened lipids in the Meibomian glands to become detached. The device is applied on the external surface of the eyelids giving a gentle massage. The procedure lasts between 8 to 12 minutes per eye.

Demodex infestation is an etiological factor for chronic blepharitis, conjunctival inflammation and $\mathrm{MGD}^{12}$. There is a correlation between age and Demodex number, and is observed in up to $100 \%$ of the elderly ${ }^{13}$.

It is now known that, in most patients, weekly eyelid cleaning with $50 \%$ tea tree oil and daily eyelid cleaning with tea tree shampoo, are effective for the eradication of Demodex infestation after use during 4 weeks ${ }^{8,12}$. Tea tree oil is known for its antibacterial, antifungal, acaricidal and anti-inflammatory properties, so its therapeutic effect may be independent of its antimicrobial effect ${ }^{12,13}$.

The anti-inflammatory activity of tea tree oil is due to the inhibition of inflammatory mediators produced by monocytes activated by lipopolysaccharidases such as tumor necrosis factor alpha (TNF- $\alpha$ ), interleukin-1 beta (IL-1ß), and interleukin-10 (IL-10), interleukin-8 (IL-8), prostaglandin-E2 ${ }^{14}$.

\section{Objective}

To compare the efficacy between a thermoelectric heating device (MiBoFlo Thermoflo ${ }^{\circledR}$ ), eyelid cleaning with tea tree shampoo and conventional eyelid cleaning in elderly patients with Meibomian gland dysfunction in the Cornea and refractive surgery department of the Hospital de la Luz, by means of the objective description of dry eye severity, gland assessment and patient symptomatology. 


\section{Methods}

A prospective, interventional, longitudinal and comparative study was carried out, which was approved by the ethics committee of the Hospital de la Luz (number 2016C4B) and followed the Regulations of the General Health Law on Health Research. An informed consent that thoroughly explained the nature and possible consequences of the study was obtained from all the participants.

A total of 41 elderly patients were included through consecutive enrollment, with diagnosis of Meibomian gland dysfunction assessed by the Cornea and Refractive Surgery Department of the Hospital de la Luz from May to September 2016.

The inclusion criteria were patients older than 60 years of both genders, willing to participate in the study, with chronic symptoms of burning, foreign body sensation or itching in both eyes, with a diagnosis of Meibomian gland dysfunction determined by meiboman gland expression, according to the method described by Friedland, et al. ${ }^{1}$, and patients with a score of 9 or less from a maximum of 15 points.

Patients with structural abnormalities of the eyelid, such as entropion, trichiasis or distichiasis, inflammation or active ocular infection of the ocular surface, trauma or ocular surgery within 3 months, allergy to tea tree oil shampoo, contact lens wearers, as well as the use of steroids, antihistamines and topical anti-inflammatories within 3 months.

\section{Study design}

Patients were consecutively divided into 3 groups. Group I (30 eyes): patients underwent 3 treatment sessions with MiBoFlo Thermoflo ${ }^{\circledR}$, lasting 8 minutes per eye, for 3 consecutive weeks. Group II (26 eyes): patients performed eyelid cleaning with $5 \%$ tea tree shampoo of the same brand twice daily for 4 weeks. Patients were trained to mix $0.5 \mathrm{~mL}$ of tea tree shampoo with $2 \mathrm{~mL}$ of running water between the two middle fingers and then perform a medium-pressure eyelid massage with the eyes closed for 3 minutes, and finally rinse with water. Group III (26 eyes): control, patients performed eyelid cleaning with baby shampoo every 24 hours for 4 weeks. Patients used a shampoo of the same commercial brand that contains cocamidopropyl betaine, sorbitan laurate, peg- 80 , sodium trideceth sulfate, among others.

Ophthalmological examination was performed on all patients with a baseline measurement, and then 4 and 8 weeks after treatment.

\section{Study parameters}

The effectiveness parameters assessed were the baseline secretion test with anesthesia, tear breakup time (TBUT), ocular surface staining with fluorescein and gland secretion score:

- Baseline secretion test with anesthesia: a paper strip (Tear $\mathrm{Flo}^{\mathrm{TM}}$ Measurement Strips) was placed in the outer third of the lower fornix after instilling a drop of topical anesthesia ( $5 \mathrm{mg} / \mathrm{mL}$ tetracaine) in the lower cul de sac. After 5 minutes, the strip was removed and the moistened millimeters were measured and recorded.

- TBUT: Fluorescein was instilled using sterile strips in the lower cul-de-sac and TBUT was immediately measured after blinking.

- Ocular surface staining with fluorescein: after instillation of fluorescein in the lower cul de sac, cornea and conjunctival staining was observed and graded using the Oxford classification system.

- Meibomian gland secretion score that included meibum quality and expressibility.

Diagnosis of MGD, according to the method described by Friedland, et al., consists in an evaluation of the presence or absence of secretion of the 5 central glands of the lower eyelid of both eyes, grading a score of 0 to $3(0=$ no secretion, $1=$ thick secretion, $2=$ turbid liquid secretion, 3 = transparent liquid secretion).

Meibomian secretion quality was evaluated in each of the eight glands of the central third of the lower eyelid on a scale of 0 to 3 for each gland: $0=$ clear Meibomian secretion, 1 = turbid Meibomian secretion, $2=$ turbid with granules, $3=$ thick, like toothpaste [range 0-24]. Meibomian secretion expressibility was evaluated in 5 glands: $0=$ all expressible glands, $1=3-4$ expressible glands, $2=1-2$ expressible glands, $3=$ no expressible gland. The evaluation was made on the upper or lower eyelid.

- Dry eye symptoms assessment by the OSDI (Ocular Surface Disease Index) questionnaire. The OSDI consists in 12 questions with a scale from 0 to 100 , with the highest scores representing the greatest disability.

\section{Thermoelectric heating device}

The MiBoFlo Thermoflo ${ }^{\circledR}$ uses a thermoelectric heat pump that distributes a constant level of heat through an ultrasonic probe that contains two pads in its distal portion. The probe is applied on the external eyelid surface with a gentle massage for 8 minutes per eye. 
Rev Mex Oftalmol (Eng). 2018;92

Table 1. Baseline characteristics of patients

\begin{tabular}{|c|c|c|c|c|}
\hline & $\begin{array}{l}\text { Thermoflo } \\
\text { group }(n=15)\end{array}$ & $\begin{array}{l}\text { Tea tree oil shampoo } \\
\text { group }(n=13)\end{array}$ & $\begin{array}{c}\text { Control } \\
\text { group }(n=13)\end{array}$ & ${ }_{\infty}^{* p}$ \\
\hline Males $\mathrm{N}^{\circ}(\%)$ & $3(20)$ & $6(46.15)$ & $4(30.76)$ & 0.34936 \\
\hline Age (years) & $69.93(7.43)$ & $69.46(9.02)$ & $69.61(4.31)$ & 0.984 \\
\hline \multirow[t]{2}{*}{ OSDI mean (SD) } & $55.19(25.27)$ & $50.10(25.14)$ & $37.32(23.88)$ & 0.166 \\
\hline & $n=30$ & $n=26$ & $n=26$ & 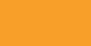 \\
\hline TBUT mean (SD) & $3.73(1.83)$ & $3.38(1.47)$ & $3.38(1.47)$ & 0.644 \\
\hline Oxford mean (SD) & $6.3(2.47)$ & $6.26(2.06)$ & $5.84(2.18)$ & 0.789 \\
\hline Baseline secretion with anesthesia mean (SD) & $12.73(7.88)$ & $9.38(7.08)$ & $9.65(4.89)$ & 0.125 \\
\hline Meibum quality mean (SD) & $14.20(4.58)$ & $15.07(4.12)$ & $12.46(5.06)$ & 0.12 \\
\hline Meibum expressibility mean (SD) & $1.63(0.80)$ & $1.73(0.45)$ & $1.46(0.70)$ & 0.356 \\
\hline
\end{tabular}

*The ANOVA test was performed.

SD: standard deviation; OSDI: ocular surface disease index; TBUT: tear breakup time.

Tissues absorb the heat emitted at $42^{\circ} \mathrm{F}$, which causes the hardened lipids in the Meibomian glands to become detached.

\section{Statistic analysis}

Performed using the SPSS program. Analysis of variance (ANOVA) between groups was used for repeated measurements using the Greenhouse-Geisser model. A p-value of less than 0.05 was considered statistically significant.

\section{Results}

A total of 41 patients (82 eyes), 28 women and 13 men, elderly (mean age $69.68 \pm 7.02$ years) with a diagnosis of Meibomian gland dysfunction were included. The baseline characteristics of the participants were compared, and no statistically significant differences were found between groups (Table 1).

\section{Dry eye syndromes}

A decrease in OSDI score was observed in the three treatment groups, reflecting a decrease in dry eye symptoms and severity; however, the changes were not statistically significant between groups $(p=0.06)$ (Fig. 1-A, Table 2).

\section{Tear breakup time}

An increase in TBUT mean was observed in the three no statistically significant differences between groups $(p=0.24)$ (Fig. 1-B, Table 2).

\section{Ocular surface staining with fluorescein using the Oxford classification}

There was a statistically significant decrease in the Oxford score between groups $(p=0.004)$ (Figure 1-C). The Thermoflo ${ }^{\circledR}$ group presented the greatest reduction in the Oxford mean value (Table 2).

\section{Baseline secretion test with anesthesia}

No statistically significant changes were observed in the baseline secretion test with anesthesia score between groups ( $p=0.891)$ (Fig. 1-D, Table 2).

\section{Gland secretion score: meibum quality and expressibility}

\section{MEIBUM QUALITY}

A statistically significant difference was observed in meibum quality between groups as the score of the characteristics of the gland secretion decreased (Fig. 1-E), which was observed from the baseline measurement up to 4 weeks and persisted until 8 weeks $(p=0.001)$ (Table 2).

\section{MEIBUM EXPRESSIBILITY}

A statistically significant difference was observed in meibum expressibility between groups $(p=0.02)$, with 

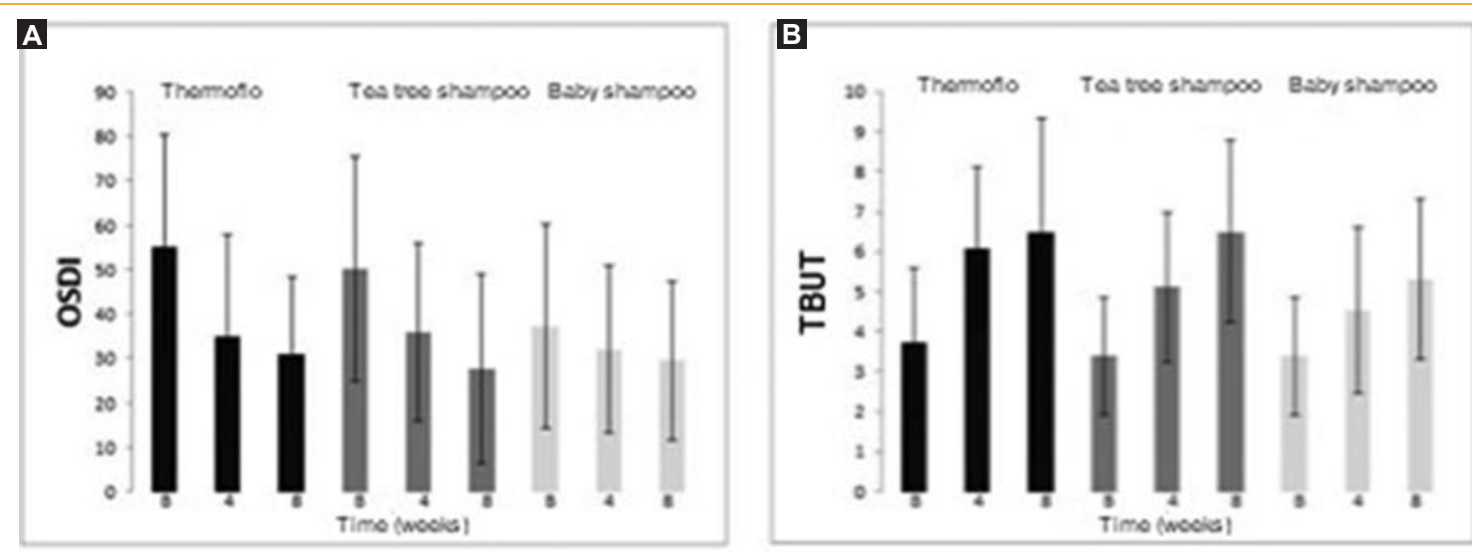

C

D
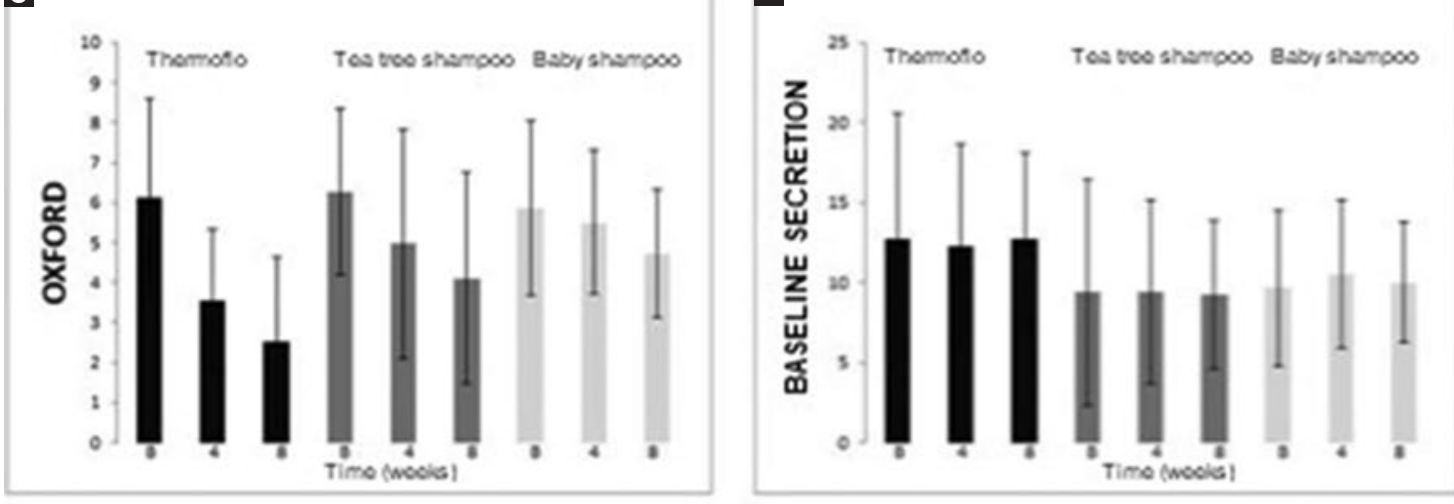

$\mathbf{E}$

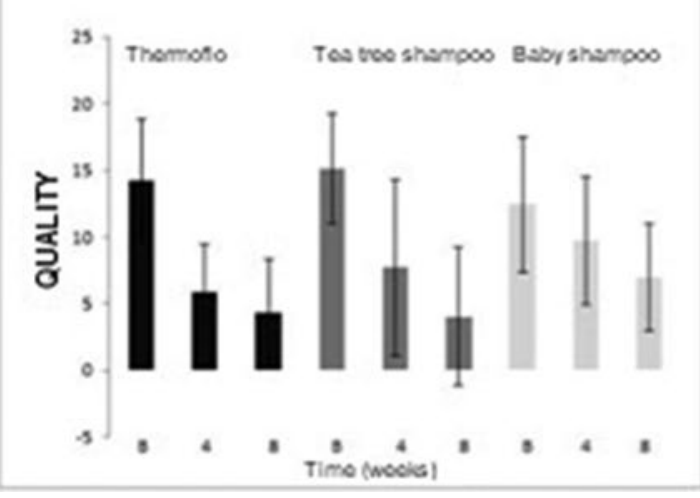

$\mathbf{F}$

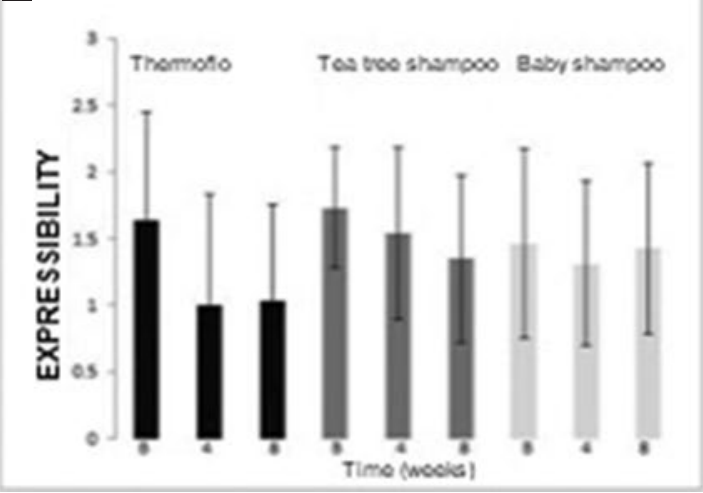

Figure 1. OSDI (A), TBUT (B), Oxford (C), baseline secretion with anesthesia (D), meibum quality (E) and meibum expressibility (F) results of the groups in the different time intervals from treatment start. The height of the bars indicates the value of the mean, the error bars indicate the standard deviation.

the Thermoflo ${ }^{\circledR}$ group showing the greatest increase (Fig. 1-F, Table 2).

\section{Discussion}

Although the conventional treatment for Meibomian gland dysfunction is the use of warm compresses and baby shampoo, there are emerging and more specific treatments, with a more specific approach to the multiple etiologies of this condition ${ }^{1,2,8,10}$.

In the case of our patients in the MiBoFlo Thermoflo ${ }^{\circledR}$ group, three treatment sessions of 8 minutes per eye were applied for 3 consecutive weeks. We observed an improvement in OSDI score, TBUT, fluorescein ocular surface staining score (Oxford scale) and gland secretion score (meibum quality and expressibility), and a 
Table 2. Results of OSDI, TBUT, Oxford, baseline secretion with anesthesia, quality and meibum expressibility measurements

\begin{tabular}{|c|c|c|c|c|}
\hline & $\begin{array}{l}\text { Thermoflo } \\
\text { group }(n=30)\end{array}$ & $\begin{array}{l}\text { Tea tree oil shampoo } \\
\text { group }(n=26)\end{array}$ & $\begin{array}{c}\text { Control } \\
\text { group }(n=26)\end{array}$ & $\infty^{*} p$ \\
\hline $\begin{array}{l}\text { OSDI** mean (SD) } \\
\text { Baseline } \\
4 \text { weeks } \\
8 \text { weeks }\end{array}$ & $\begin{array}{l}55.19(25.27) \\
34.79(22.98) \\
30.91(17.51)\end{array}$ & $\begin{array}{l}50.10(25.14) \\
35.90(19.93) \\
27.65(21.20)\end{array}$ & $\begin{array}{l}37.32(23.88) \\
32.05(19.56) \\
29.46(18.45)\end{array}$ & 0.06 \\
\hline $\begin{array}{l}\text { TBUT mean (SD) } \\
\text { Baseline } \\
4 \text { weeks } \\
8 \text { weeks }\end{array}$ & $\begin{array}{l}3.73(1.83) \\
6.10(2.00) \\
6.50(2.82)\end{array}$ & $\begin{array}{l}3.38(1.47) \\
5.11(1.88) \\
6.50(2.28)\end{array}$ & $\begin{array}{l}3.38(1.47) \\
4.53(2.06) \\
5.30(2.01)\end{array}$ & 0.24 \\
\hline $\begin{array}{l}\text { Oxford mean (SD) } \\
\text { Baseline } \\
4 \text { weeks } \\
8 \text { weeks }\end{array}$ & $\begin{array}{l}6.13(2.47) \\
3.53(1.79) \\
2.53(2.09)\end{array}$ & $\begin{array}{l}6.26(2.06) \\
4.96(2.84) \\
4.11(2.64)\end{array}$ & $\begin{array}{l}5.84(2.18) \\
5.50(1.79) \\
4.73(1.58)\end{array}$ & 0.004 \\
\hline $\begin{array}{l}\text { Baseline secretion with anesthesia mean (SD) } \\
\text { Baseline } \\
4 \text { weeks } \\
8 \text { weeks }\end{array}$ & $\begin{array}{l}12.73(7.88) \\
12.23(6.45) \\
12.70(5.37)\end{array}$ & $\begin{array}{l}9.38(7.08) \\
9.42(5.72) \\
9.23(4.60)\end{array}$ & $\begin{array}{l}9.65(4.89) \\
10.50(4.65) \\
10.00(3.77)\end{array}$ & 0.891 \\
\hline $\begin{array}{l}\text { Meibum quality mean (SD) } \\
\text { Baseline } \\
4 \text { weeks } \\
8 \text { weeks }\end{array}$ & $\begin{array}{l}14.20(4.58) \\
5.86(3.59) \\
4.26(4.05)\end{array}$ & $\begin{array}{l}15.07(4.12) \\
7.69(6.58) \\
4.00(5.18)\end{array}$ & $\begin{array}{l}12.46(5.06) \\
9.73(4.77) \\
6.96(4.03)\end{array}$ & 0.001 \\
\hline $\begin{array}{l}\text { Meibum expressibility mean (SD) } \\
\text { Baseline } \\
4 \text { weeks } \\
8 \text { weeks }\end{array}$ & $\begin{array}{l}1.63(0.80) \\
1.00(0.83) \\
1.03(0.71)\end{array}$ & $\begin{array}{l}1.73(0.45) \\
1.53(0.64) \\
1.34(0.62)\end{array}$ & $\begin{array}{l}1.46(0.70) \\
1.30(0.61) \\
1.42(0.64)\end{array}$ & 0.02 \\
\hline
\end{tabular}

statistically significant difference between groups on the Oxford scale, and meibum quality and expressibility. The MiBoFlo Thermoflo ${ }^{\circledR}$ group showed the greatest increase in expressibility. There is a study of MiBoFlo Thermoflo ${ }^{\circledR}$ that reports preliminary data of 51 patients, and found an improvement in TBUT, osmolarity and OSDI score at 4 months after three treatment sessions. Unlike our study, the treatment protocol used was 12 minutes per eye, then 10 minutes per eye one week later and 8 to 10 minutes per eye 2 weeks later ${ }^{15}$. The increase in gland expressibility in these patients is due to the absorption by tissues of the heat emitted by the probe, which produces fluidification of the hardened lipids of Meibomian glands and secondarily improves the stability of the lipid layer of the tear film.

Friedland, et al. conducted a multicenter clinical trial in which 14 patients with obstructive-type MGD were studied, who underwent a 12-minute treatment session with LipiFlow ${ }^{\circledR}$ (vector thermal pulsation therapy, which is similar to Thermoflo ${ }^{\circledR}$ ). They found a significant improvement in dry eye symptoms, gland secretion score, ocular surface staining and TBUT, maintained during the 3-month follow-up ${ }^{1}$. They report results similar to our study in terms of improvement of the parameters evaluated; however, there are differences in the characteristics of the study. For example, the mean age of these patients was $54.2 \pm 9.6$ years compared to 69.68 \pm 7.02 years in our study; also, the treatment session duration was 1 session of 12 minutes for LipiFlow ${ }^{\circledR}$ compared to 3 sessions of 8 minutes in our study.

However, other authors have conducted similar studies where not all the parameters studied have shown statistical significance. Blackie, et al., in a review article that included 31 studies with LipiFlow ${ }^{\circledR}$, found that all of them reported an increase in Meibomian gland function and symptoms improvement after a 12-minute treatment session ${ }^{16}$.

Zhao, et al. compared LipiFlow ${ }^{\circledR}$ (one session) àgainst warm compresses (every 12 hours for 3 months), and found an improvement in dry eye symptoms at 3 months in both groups and an increase in TBUT in the thermal pulse group at 1 month of treatment. It should 
be noted that the mean age of these patients was 56.4 $\left( \pm\right.$ 11.4) for LipiFlow ${ }^{\circledR}$ and $55.6( \pm 12.7)$ for the warm compresses group ${ }^{17}$.

In addition to the mechanical treatment modalities, there are multiple pharmacological treatments available, such as antibiotics, steroids, immunomodulators and tea tree $\mathrm{oil}^{8}$. Tea tree oil is obtained from the plant Melaleuca alternifolia and is known for its bactericidal, antifungal, acaricidal and anti-inflammatory properties $^{12,13}$. Tea tree oil is included in several shampoos at different concentrations ${ }^{8}$, and weekly eyelid cleaning with $50 \%$ tea tree oil and daily eyelid cleaning with tea tree shampoo have been described as effective for the eradication of Demodex infestation after use for 4 weeks in most patients, which may improve the symptoms associated with $M G D^{12,13}$.

In the case of our patients who performed eyelid cleaning with $5 \%$ tea tree shampoo twice a day for 4 weeks, we found an improvement in OSDI, TBUT, ocular surface staining with fluorescein (Oxford scale) and meibum quality and expressibility. No other studies on the use of tea tree oil shampoo in patients with MGD were found to date. Koo, et al. performed a study of eyelid cleaning with tea tree oil in patients with Demodex-associated blepharitis, and found an improvement in dry eye symptoms ${ }^{12}$; its therapeutic effects can be independent of its antimicrobial and acaricidal effect, since it has anti-inflammatory activity.

The parameter that showed no differences was the baseline secretion test with anesthesia. There are several limitations and biases that may arise during its performance that may be a consequence of the contact of the paper with the eyelashes, causing a physiological reflex arc that cannot be suppressed by topical anesthetics, in addition to other factors as humidity, light or patient's anxiety. The literature reports a wide range of sensitivity and specificity values for this test ${ }^{18}$.

The limitations of the study may be associated with several factors that influence the diagnosis of dry eye, the limited availability of a thermoelectric heating device and the costs derived from the treatment sessions; as well as the sample size since the enrollment of the groups was consecutive and not randomized. It is important to mention that patients in the group treated with MiBoFlo Thermoflo ${ }^{\circledR}$ and tea tree oil had a more severe disease by OSDI (baseline) compared to the control group, so this could influence the magnitude of the difference observed in symptoms; however, no statistically significant differences were observed between baseline patient measurements. It should be noted that changes at the level of Meibomian glands associated with age have been described, such as a decrease in the proliferation of acinar cells and gland atrophy, with a consequent decrease in the lacrimal lipid layer, increased evaporation and tear film instability 3,9 .

\section{Conclusion}

Apparently, Thermoflo ${ }^{\circledR}$ and tea tree shampoo treatment were superior compared to conventional eyelid cleaning with baby shampoo to improve patient symptoms and signs associated with MGD. The thermoelectric heating device seems to be superior in producing a greater increase in the expressibility of Meibomian glands, although the availability of the equipment and treatment costs must be taken into consideration.

\section{Conflicts of interest}

The authors do not have commercial interest of any kind.

\section{Ethical disclosures}

Protection of human and animal subjects. The authors declare that the procedures followed were in accordance with the regulations of the relevant clinical research ethics committee and with those of the Code of Ethics of the World Medical Association (Declaration of Helsinki).

Confidentiality of data. The authors declare that no patient data appear in this article.

Right to privacy and informed consent. The authors declare that no patient data appear in this article.

\section{References}

1. Friedland BR, Fleming CP, Blackie CA, Korb DR. A novel thermodynamic treatment for meibomian gland dysfunction. Current eye research. 2011;36(2):79-87.

2. Nakayama N, Kawashima M, Kaido M, Arita R, Tsubota K. Analysis of Meibum Before and After Intraductal Meibomian Gland Probing in Eyes With Obstructive Meibomian Gland Dysfunction. Cornea. 2015;34(10): 1206-8.

3. Jester JV, Parfitt GJ, Brown DJ. Meibomian gland dysfunction hyperkeratinization or atrophy? BMC ophthalmology. 2015;15 Suppl 1:156.

4. Baudouin C, Messmer EM, Aragona P, Geerling G, Akova YA, Benitez-Del-Castillo J, et al. Revisiting the vicious circle of dry eye disease: a focus on the pathophysiology of meibomian gland dysfunction. $\mathrm{Br}$ J Ophthalmology. 2016;100(3):300-6. PubMed PMID: 26781133. Pubmed Central PMCID: 4789719.

5. Nichols KK, Foulks GN, Bron AJ, Glasgow BJ, Dogru M, Tsubota K, et al. The international workshop on meibomian gland dysfunction: executive summary. Investigative ophthalmology \& visual science. 2011;52(4): 1922-9.

6. Cárdenas Díaz T, Hernández López I, Guerra Almaguer M, Cruz Izquierdo D, Miranda Hernández I, Montero Díaz E. Conceptos actuales en la disfunción de las glándulas de Meibomio. Revista Cubana de Oftalmología. 2014;27(2):264-71 
Rev Mex Oftalmol (Eng). 2018;92

7. Alghamdi YA, Mercado C, McClellan AL, Batawi H, Karp CL, Galor A Epidemiology of Meibomian Gland Dysfunction in an Elderly Population. Cornea. 2016;35(6):731-5

8. Thode AR, Latkany RA. Current and Emerging Therapeutic Strategies for the Treatment of Meibomian Gland Dysfunction (MGD). Drugs. 2015; 75(11):1177-85

9. Chhadva P, Goldhardt R, Galor A. Meibomian Gland Disease: The Role of Gland Dysfunction in Dry Eye Disease. Ophthalmology. 2017;124(11S): S20-S6.

10. Qiao J, Yan X. Emerging treatment options for meibomian gland dysfunction. Clin Ophthal. 2013;7:1797-803.

11. Lane SS, DuBiner HB, Epstein RJ, Ernest PH, Greiner JV, Hardten DR et al. A new system, the LipiFlow, for the treatment of meibomian gland dysfunction. Cornea. 2012;31(4):396-404.

12. Koo H, Kim TH, Kim KW, Wee SW, Chun YS, Kim JC. Ocular surface discomfort and Demodex: effect of tea tree oil eyelid scrub in Demodex blepharitis. Journal of Korean medical science. 2012;27(12):1574-9.
13. Geerling G, Tauber J, Baudouin C, Goto E, Matsumoto Y O'Brien T, et al. The international workshop on meibomian gland dysfunction: report of the subcommittee on management and treatment of meibomian gland dysfunction. Investigative ophthalmology \& visual science. 2011;52(4):2050-64.

14. Carson CF, Hammer KA, Riley TV. Melaleuca alternifolia (Tea Tree) oil: a review of antimicrobial and other medicinal properties. Clin Microbiol Rev. 2006;19(1):50-62.

15. website TMcr. TearScience. MiBo clinical research website http://mibomedicalgroup.com/clinical-research/2016 [cited 2016 April 2.

16. Blackie CA, Carlson AN, Korb DR. Treatment for meibomian gland dysfunction and dry eye symptoms with a single-dose vectored thermal pulsation: a review. Curr Op Ophthalmol. 2015;26(4):306-13.

17. Zhao Y, Veerappan A, Yeo S, Rooney DM, Acharya RU, Tan JH, et al. Clinical Trial of Thermal Pulsation (LipiFlow) in Meibomian Gland Dysfunction With Preteatment Meibography. Eye Contact Lens. 2016;42(6):339-46.

18. Alegría-Gómez ED, Baca-Lozada O. Evaluación de la película lagrimal. En: Córnea Médica. 1.a ed. México: Elsevier; 2015. p. 43-51. 